\title{
La fauna exótica en la Península Ibérica: apuntes para el estudio del coleccionismo animal en el Medievo hispánico
}

\author{
Dolores Carmen Morales MuÑIZ
}

\begin{abstract}
RESUMEN ABSTRACT
Por sus especiales circunstancias, la

Probably due to its strategic geographical position, the Iberian peninsula has enjoyed a privileged condition in terms of fluxes of exotic faunas throughout history. This paper reviews the role played by exotic faunas in Medieval Spain, in particular with reference to the creation of zoos and zoological parks at large. In addition, a brief consideration is made about aspects related to the introductions of autochtonous species at various places of the iberian territory itself as well as extinction events of certain taxa or stocks.
\end{abstract}

INTRODUCCIÓN: OBJETO Y MÉTODO

El estudio de la fauna, en general, y más cuando se trata de especies silvestres, en la época medieval, plantea al historiador problemas varios. La zoología, como ciencia, es una disciplina que tiene tres siglos. Su metodología, además, resulta ser muy diferente a la de las disciplinas humanísticas. Intentar conciliar las dos resulta una tarea harto difícil ya que la historia, por definición, es científica, en el sentido de rigurosa, por su forma 
de construirse pero no es comprobable como las matemáticas. A esto le añadimos trabajar en una época, la medieval, que no es precisamente la Inglaterra de Newton, científicamente hablando.

Un zoólogo suele dudar, con frecuencia, de la información de las fuentes escritas...y si tienen muchos siglos, mucho más. El primer escollo para estudiar la fauna surge, sobre todo a nivel etimológico/conceptual. P.e. un cronista habla de un toro muy bravo que vive con otras «animalías», a las que ocasiones también llama «fieras», que anda vagando por tierras de Coca, a finales del siglo $x \mathrm{v}$, junto con cabras montesas $\mathrm{y}$ otros cérvidos. ¿Qué es bravo? ¿silvestre? ¿se trata quizás de un uro? Resulta que el uro estaba extinguido mucho antes de escribirse la crónica en cuestión. Otro ejemplo, en esta ocasión procedente de una fuente jurídica: el Código de las Siete Partidas de Alfonso $X$ el Sabio. Prestigiosísima como fuente de información para especialistas varios, las Partidas, le plantean problemas a un zoólogo. Cuando el monarca en la Partida 3, Título XVIII, habla de onzas, leones... ¿a qué llama una onza? ¿A una pantera? ¿A un guepardo? ¿Es el leopardo y la pantera el mismo animal? Estas son las preguntas que haría un zoólogo a un historiador. Generalmente el último, a juzgar por la ingente producción sobre zoohistoria, diría ¿y qué importa?. Naturalmente las preguntas del zoólogo no se pueden contestar salvo que tengamos testimonio iconográfico o se conserven restos de los animales. Casi nunca ocurre esto. Pero cuando sí se produce, los errores no se solventan porque los historiadores del arte no siempre hablan con los zoólogos,y viceversa, de forma que se perpetua lo que en un primer momento pudo decir alguien sin comprobación. Tomemos como ejemplo los famosísimos frescos de la Capilla de los Magos, en el Palacio Medici Ricardi de Florencia. El autor, Benozzo Gozzoli, plasmó en aquel cortejo, con el que se conmemoraba el fin del concilio de Ferrara (1439) bastantes animales, la mayoria de las especies, pintadas del natural, nos dicen, no son europeas: camellos, monos y ...guepardos. Fijémonos en el último. El animal que aparece sentado en la grupa del caballo con cadena lujosa es... un lince. También lo es el que aparece en primer término de pie,con el cortejo a caballo. Una pareja de linces, pues. Pero seguimos diciendo guepardos. ¿Es que no sabemos distinguirlos? O mejor, ¿es así como podían denominar al lince en la Florencia del xv? $\mathrm{O}$, simplemente, ¿se trata de un error perpetuado siglo tras siglo? Total: nosotros sabemos, con la ayuda del zoólogo, que la especie que aparece pintada no es un leopardo sino un lince.

Casi nunca podemos asegurar que estamos ante el animal que dice el cronista, el viajero, el dato de la aduana, la orden para la manutención del citado animal o la carta del monarca de turno pidiendo que le importen 
unos animales de Mallorca que resulta que no son ciervos, como dice la escritura, porque en Mallorca no había ciervos, sino... ¿gamos quizás? En definitiva, para un zoólogo del siglo XXI los historiadores sólo tendríamos un indicio, que puede variar en fiabilidad, según la fuente, de la existencia de este animal. Nunca la seguridad. La fuente escrita es así.

El problema, es, muchas veces, etimológico. ¿como sabemos que el animal citado es el que nosotros hoy denominamos así? ¿es un lince siempre un lince? Resulta que al lince le podian llamar gato o lobo cerval y luego las fuentes documentales citan otros gatos silvestres -rabudo, clavo...- que uno no sabe ni de que especie se trata. ¿sería, simplemente, un gato montés? En los tiempos medievales y aun modernos no existía una nomenclatura rigurosa.

Los escritores medievales, fueran clérigos, juristas, naturalistas, o comerciantes no distinguían entre familias,especies, géneros, clases, órdenes...la clasificación científica es muy posterior. Añadimos, además, otro escollo. Quien cita al animal no siempre lo describe, y si lo hace, puede verse influido por un sinfín de cargas ideológicas que proceden desde los Bestiarios hasta el miedo que produce la visión del animal. Otras veces hablan de oído.

En un primer momento la reacción es no escribir sobre una disciplina altamente rigurosa y muy moderna, metodológicamente hablando, la zoología, con una información histórica altamente dudosa por la época, la misma naturaleza de las fuentes y además porque quien la produce no tiene demasiada conciencia de lo importante que resulta para un zoólogo actual si cuando se dice melo se refieren a la mangota o cual es el motivo por el que se dice mono en un sitio y bogia en otro. A esto hay que añadir que el vocabulario medieval es variadísimo de un punta a otra del país, ¿no es verdad que una fuina, en bable, pero también en aragonés, es lo que se llama, en castellano, garduña (Martes foina) ¿y si llamaran fuina a otra especie? No lo podemos saber.

Si consultamos en diccionarios etimológicos la primera vez que se han citado a los animales nos encontraríamos con fuentes escritas, muchas de ficción, y, de nuevo, nadie nos aseguraría que estuviéramos hablando del mismo animal. ¿No es verdad que los españoles cuando llegaron a América llamaron — quizás siguiendo a los aztecas- leones a los pumas, y los portugueses aplicaron el término de encebro, un asno salvaje, hoy extinguido, para referirse a las cebras? ¿No es cierto, que entre otros muchos casos de confusión de las especies, los Bestiarios medievales denominan uro al antílope?

Quien este trabajo escribe es historiadora. A pesar de todos los problemas anteriormente expuestos intentará realizar un trabajo riguroso - si 
bien no con precisión matemática- con los datos proporcionados por fuentes históricas escritas y con toda la carga de inseguridad que los problemas etimológicos y conceptuales implican. Como toda investigación pionera la zoohistoria se encuentra con estas dificultades, lo que no impedirán seguir trabajando desde la interdisciplinariedad como se ha demostrado en otros trabajos ${ }^{1}$.

El objeto de este trabajo es claro: sistematizar la información procedente de fuentes y trabajos que ya han tratado este tema para contribuir al estudio de los zoológicos medievales. Secundariamente se tratará la introducción de especies que, en algún caso, todavía perviven en nuestra fauna actual o perduraron durante mucho tiempo. La invasión musulmana es la referencia esencial para tratar esta última cuestión. Por razones de espacio nos concentraremos en los animales llamados exóticos, es decir, especies no europeas muy valoradas para coleccionar, haciendo referencia al contexto europeo.

\section{Zoología: los conocimientos teóricos}

¿Que sabía el hombre medieval hispano de los animales incluidos los exóticos..? En España, como en el resto de Europa, la zoología medieval fue hija de su pasado clásico siendo la referencia de autoridad recurrente Aristóteles. Incluida en las llamadas ciencias naturales, la zoología no fue una ciencia especialmente cultivada en el medievo. Para compensarlo contamos con un importante conocimiento sobre animales facilitada por la información de viajeros, geógrafos, filólogos, así como por tratados agrícolas, obras de caza y cetrería y otras sobre zoología aplicada o zootecnia:apicultura, sericultura, hipiatría, etc. Las tres culturas hispanas - judía, cristiana y musulmana- se vieron afectadas por la herencia de Aristóteles,y, en ningún caso, pudieron desvincularse del determinante re-

\footnotetext{
La lista de trabajos sobre Zoohistoria sería larga, y, en algún caso, aparece reseñada a lo largo de este estudio. En el año 1991 escribi, a propósito de una reseña, unas líneas sobre la importancia de esta especialidad en Medievalismo, 1, pp. 189-92. Ese mismo año desarrollé la cuestión en un trabajo más amplio: "Zoohistoria: reflexiones acerca de una disciplina histórica" Espacio, Tiempo y Forma en adelante ETF, Serie III, 4, pp. 367-83. Destaco, por su interés, la revista Antropozoologica que lleva publicándose desde 1984, cada seis meses. Asimismo, dentro de esta misma línea interdisciplinar, son destacables los Coloquios sobre los Conocimientos zooógicos que edita la investigadora Liliane Bodson, de la Universidad de Lieja, y que se publican anualmente, el último de 1999, es el número 11. El Laboratorio de Arqueozoología, único en su género, de la Universidad Autónoma de Madrid, dirigido por el catedrático de Biología Animal, Prof. Dr. Morales, publica anualmente Arqueofauna que lleva hasta la fecha nueve números publicados.
} 
ligioso. Buena parte de la herencia aristotélica se conoce en Europa por las traducciones realizadas en la península ibérica. Baste decir que la zoología de Aristóteles, traducida por Miguel Scoto en Toledo en 1230, fue la versión utilizada para que San Alberto Magno escribiera su Libro de los Animales. Pedro Gallego realizó una versión resumida del trabajo del Estagirita. También Averroes y Avicena llevaron a cabo resúmenes y paráfrasis de la obra citada ${ }^{2}$.

En este sentido, gracias a la presencia árabe y judía, a España le correspondió un protagonismo especial. Los siglos de dominio musulmán se caracterizaron por unas relaciones comerciales muy importantes. La cercanía geográfica con el mundo norteafricano también privilegió a la península ibérica a la hora de conseguir animales, particularmente de los que hemos denominado exóticos.

\section{El coleccionismo animal: poder y lujo}

El hábito de coleccionar animales y particularmente animales salvajes y exóticos parece perderse en la noche de los tiempos. De Oriente a Occidente -Egipto, China, Roma...- se conserva información sobre esta práctica. Los motivos que llevaban a conservar animales en parques o jardines respondían a motivos parecidos si bien en Roma sabemos que el interés por los animales estaba muy relacionado con las prácticas del circo. Durante siglos las masas acudieron a contemplar a los gladiadores batirse con animales y a estos entre sí. Las cifras proporcionadas por los especialistas son escalofriantes. Cientos de miles de animales fueron trasladados desde sus lugares de origen siendo masacrados en lo que hoy no dudariamos en calificar como desastre ecológico ya que muchas especies quedaron sumamente mermadas extinguiéndose no pocas en muchas de sus zonas de origen ${ }^{3}$.

2. Ver el capítulo que sobre la zoología musulmana ha escrito J. VERNET en Lo que Europa debe al Islam de España, pp. 374 y ss., Barcelona, 1999. También, sobre la misma cuestión, ver algunos trabajos dentro de la obra Ciencias de la Naturaleza en Al Andalus escrita por diferentes autores y que consta con varios volúmenes publicados por el CSIC en Granada. Es muy interesante el vol. 5 particularmente el trabajo de A. M. CABO GonzÁLEZ: «El reino animal en el Kitab al Yami. Fuentes utilizadas por Ibn-Baytar», pp. 21-55, así como también estudio, en el mismo volumen de M. Arcas Campoy «Referencias zoológicas en los tratados del derecho islámico», pp. 1119, Granada, 1998.

3 Para los datos sobre la extinción de los animales ver R. Delort: Les Animaux ont une histoire, pp. 109, París, 1984 y también J. W. Grieg y T. Burk: Biology of Animal Behavior, pp. 785-6, N. York, 1992. 
En el mundo oriental, en cambio, la costumbre de mantener animales en cautividad respondía a fines más lúdicos. La fauna, además, representaba símbolos asociados con el poder por lo que su mantenimiento era signo de estatus social y de riqueza. De hecho solían ser utilizados animales en desfiles, divertimentos, paseos... asociados con un simbolismo inequívoco. Esto resulta especialmente aplicable a la edad media occidental en donde se perpetuaron las llamadas menageries o casas de fieras, sin cortes bruscos con la tradición clásica salvo en casos concretos como la colección inglesa de Woodstock sin nada que ver con el pasado romano, y, naturalmente, todas las que surgen en lugares donde, en época clásica, se vivía, como mucho en la protohistoria, esto es, Europa centro oriental y nórdica ${ }^{4}$.

Es cierto que, cuantitativa y cualitativamente hablando, los zoológicos medievales no parecen comparables a los del mundo antiguo salvo en etapas muy avanzadas, casi renacentistas pero, aparte de volver a subrayar que buena parte de Europa no había nacido a la historia ni tenía el grado de desarrollo de países orientales, caso, por ejemplo, de China, habría que revisar determinadas apreciaciones reduccionistas sobre la inexistencia de zoológicos en los siglos medievales hasta bien avanzado el siglo $x v$ ya que, a menudo, lo que a primera vista sí parece claro es que el tema no se ha trabajado apenas probablemente debido a una limitación en las fuentes.

Los animales silvestres acaparaban la atención en el mundo medieval como se demuestra en el género pseudocientífico y moralista de los Bestiarios - herederos de los Fisiologi- y en la iconografía, en parte determinada por el contenido de aquellos. Pintura y escultura, pero también artes menores y, sobre todo, manuscritos iluminados se nos muestran con una animalística impresionante. A los animales salvajes se les asociaba con el plan dispuesto por Dios y más propiamente con la naturaleza, que a los domesticados por el hombre. Dentro del pensamiento trascendente, de la espiritualidad monástica y de la intelectualidad clerical, los animales no domesticados jugaban un gran papel insertándose dentro del plan pacificador universal, previsto en el orden divino. Asi, por ejemplo, las fieras quedaban amansadas ante la presencia de la santidad, del hombre de

\footnotetext{
4 Aparte de los dos libros reseñados en la anterior cita han sido interesantes, para conocer los zoológicos medievales los trabajos de M. SCHNECK: The Word of Nature, N. York, 1990 y de J. FISHER: Animales Exóticos, Pamplona, 1968. Sin embargo, a pesar del tiempo transcurrido, la referencia inevitable y más completa sigue siendo el estudio que G. LoISEL publicó en París en 1912, Histoire des Menageries de L'Antiqué a nos jours.
} 
Dios (vir Dei) incluso del hombre fuerte como queda reflejado en el Poema del Mio Cid, en el episodio de los condes de Carrión, cuando El Campeador, sólo con su presencia, amansa a un bravo león. Los animales, son, además, un ejemplo de la naturaleza comparándose su situación con la del monje en la soledad. San Juan Crisóstomo hablaba de ser «sano de cuerpo como los animales salvajes» ${ }^{5}$.

Cuatro parecen las causas que explican el coleccionismo animal en los tiempos medievales: la pervivencia de los combates y juegos de animales, la caza, los regalos intercambiados entre mandatarios, y, naturalmente, el comercio. Las diferencias regionales determinan que una u otra causa sea preferente para explicar el fenómeno y desarrollo de las menageries en cada país.

Francia parece acaparar prácticamente las cuatro causas mencionadas si bien inicialmente la pervivencia de los combates de animales que procuraban la conservación de aquellos que tomaban parte en los espectáculos, parece ser condicionante a la hora de hablar de zoológicos medievales. El cristianismo fue determinante para el continuo debilitamiento de esta causa ya que siempre mantuvo una posición enérgicamente de condena y prohibición de los juegos. Cuando se afirma que la relación hombre/animal dentro de la concepción cristiana, está basada en el antropocentrismo y en el desprecio hacia otras formas de vida, cosa muy discutible pero que nos aleja de nuestro tema principal, se olvida, con frecuencia, que gracias a la prohibición de los juegos por parte de la Iglesia así como de los sacrificios, el trato hacia el animal fue bastante mejor que en épocas anteriores aunque lo que se buscara fuera salvaguardar la dignidad del hombre y diferenciarlo de los valores paganos de fuerza y violencia. Indirectamente, por tanto, los animales se beneficiaron de aquella actitud y no faltaron voces que defendían, per se, a los animales como San Anselmo o San Juan Crisóstomo.

La explicación más coherente para explicar el nacimiento y desarrollo de las menageries francesas es la caza. De hecho, en muchas ocasiones se pasó de una reserva o parte de caza a un zoológico sin solución de continuidad. Este parece ser el caso de la vecina Inglaterra, pero más aún de los monarcas carolingios. Algunas de sus residencias en Aix la Chapelle, Nimega, Ingelheim... contaban con especies varias de fauna, generalmente autóctona.

5 Es muy interesante el estudio que ha realizado S. SEBAstían: Iconografía Medieval, donde revisa las bases teóricas e intelectuales de la imaginería animalística, pp. 63 y ss., Donostia, 1988. 
Los regalos eran práctica habitual entre los reyes, grandes feudatarios y también eclesiásticos. Los animales eran muy estimados al simbolizar virtudes relacionadas con el ejercicio del poder y el grupo social al que se pertenecía. Así cualidades como la majestad, la fiereza, la magnanimidad, entre otras «virtudes», concepto este último, muy humano, atribuido a determinadas especies, se mostraban en todo su esplendor en desfiles y divertimentos varios. Los félidos iban sujetos por cadenas o incluso cintas y se paseaban con sus dueños. El caso típico es el de los leones aunque más adelante otros felinos se incorporaron a esta práctica. Pavos reales, faisanes y rapaces también exhibían cualidades regias. Felipe el Atrevido, duque de Borgoña, solía realizar frecuentes exhibiciones de las tres especies juntas. No es infrecuente en la pintura bajomedieval o prerrenacentista encontrarse con la plasmación de determinados animales con toda su carga simbólica. Antonello de Messina o Carpaccio pintan pavos reales y faisanes de gran realismo en cuadros religiosos de donde cabe deducir que también en la simbología no laica, los animales llevaban su carga.La Heráldica también resulta ser una fuente esencial sobre las virtudes animalísticas y así se comprueba en los escudos de armas en donde, curiosamente, fauna habitualmente con una carga simbólica negativa en ambientes religiosos se transforma positivamente en el caso laico, como el jabalí o el mismo perro ${ }^{6}$.

Por último, en este breve repaso sobre las condiciones que explican los zoológicos medievales, no podemos olvidar su desarrollo y consolidación sin referirnos al comercio. No es coincidencia que los focos comerciales más importantes de Europa, particularmente los italianos, tuvieran excelentes menageries y animales exóticos. En menor medida los Países Bajos e Inglaterra exhibieron una fauna importada junto con la propia autóctona. Se afirma que el zoológico municipal de Amsterdam se nutría de regalos de mercaderes extranjeros y que el ya citado de Woodstock albergaba especies no europeas como leopardos, leones y linces. Estos últimos, por cierto, eran considerados exóticos al haber desaparecido de Inglaterra, como los osos, desde el sigio XIII. Dentro del apartado del comercio no debe olvidarse tampoco el fenómeno para comprender no sólo la introducción de ciertos animales exóticos sino también de razas de animales

6 D. C. Morales MuÑIz: «El Simbolismo animal en la cultura medieval», ETF, Serie III, 9 , pp. 229-256, 1996, y "Los animales en el mundo cristiano-occidental: actitud y mentalidad», ETF, Serie III, II, pp. 307-330, 1998. La bibliografía sobre simbolismo animal es, asimismo, muy extensa, Recordamos dos títulos de interés Diccionnaire Symbolique des Animaux, de Dom Pierre Miquel, París, 1992, y X. R. MariÑo: Ferro Simbolismo Animal. Creencias y significados en la cultura occidental, Madrid, 1996. 
domésticos, caso del grifón tártaro (perro) o de algunos gatos. También debemos recordar la renovación de las ideas y costumbres así como el gusto por los viajes que, desde mediados de la época medieval, impregnó a los europeos. Muchos viajes de hecho se encuadraron dentro de lo que hoy llamaríamos realidad virtual. A través de la lectura, de los relatos de viajeros y misioneros, las mentes se abrieron a mundos maravillosos en donde, entre otras peculiaridades, se hallaban poblados de especies jamás vistas. El Libro de // Miglione/Las Maravillas de Marco Polo contiene numerosas referencias de animales desconocidos hasta esa fecha en Europa. Ni siquiera las fuentes clásicas los habían nombrado ${ }^{7}$.

Italia, cuyas ciudades, en gran parte comerciaban con todo el mundo conocido directa o indirectamente llevaban la delantera de Europa por lo que a exóticos se refiere. Resulta una referencia inevitable hablar de zoológico de Federico II Staufen, un ornitólogo y naturalista, con rasgos científicos, como lo demuestran sus obras. El emperador tenía tres parques de fieras permanentes en Palermo, Melfi y Lucera lo cual no evitaba que en su desplazamientos se hiciera acompañar por su animales favoritos. Esta, por cierto, era una costumbre típica de la época, la de las colecciones móviles o itinerantes. Cuando Federico II se trasladó a Worms para casarse con una hermana del rey de Inglaterra su colección móvil de elefantes, monos y felinos, le acompañaron algunos en calidad de regalos ofrecidos a su cuñado, que los trasladó a la colección particular que no tardaría en conservarse en la Torre de Londres. Woodstock se había quedado pequeño.

Los zoológicos europeos, además de especies autóctonas, cinegéticas principalmente -cérvidos, osos, jabalíes, lobos, rapaces...-, rivalizaban en mantener especies no europeas. Entre las colecciones occidentales más originales destacamos las "vacas marinas", focas, y

7 Estas son algunas de las especies descritas por Marco Polo y desconocidas para los occidentales: los yaks, los gudderi (gacelas almizcleras), la perdíz de las nieves (baherlac), las ratas del faraón o mangostas, varios tipos de monos, algunos comestibles y otros que «están extremadamente hechos y son tan gordos que parecen tratarse de hombres $s$ (¿langures?), salamanquesas ("tarántulas que son como lagartos"), zorros voladores, panteras negras ("leones negros") cacatuas («loros de muchas especies más bellos de los que se llevan a nuestros países»), varias especies de grullas, rinocerontes de Sumatra («unicornios») y puercoespines. Entre los animales más conocidos por los europeos, M. Polo describe elefantes, jirafas, avestruces, puercoespines y leones. Estos últimos, por cierto, citados en la antigua Bastres, capital de la Bactriana, ya no existen hoy en día. Como también está extinguido el lagarto monitor o de las Islas Cómodo. Asimismo el italiano describe animales extrañísimos de imposible identificación como «gallinas que no tienen plumas sino piel con pelo negro, como un gato». Lo único que no las diferenciaba de sus homónimas europeas era que su carne se comía y que ponían huevos. Ver El Libro de las Maravillas, Traducción, Apéndice y Notas de Mauro Armiño, Madrid, 1992. 
morsas de la menagerie del Gran Maestre de la Orden Teutónica en Mariemburgo. Mamíferos, aves y peces, por ese orden, eran enormemente estimados. El león siguió considerado el rey de los animales y el que mejor representaba las virtudes del equivalente humano, Si tuviéramos que caracterizar a las menageries europeas según la rareza de sus especies de nuevo nos referiríamos a las ciudades italianas, ya que hasta Roma conservó el foso del Capitolio para este fin. Era famosa la "Gueparderie" de Nápoles., pero las demás especies no le iban a la zaga: hienas, elefantes indios, faisanes dorados de la China, osos blancos -estos también presentes en los zoológicos ingleses y francesesy jirafas. Todos dejaban boquiabiertos a sus contemporáneos. $Y$ no digamos ya los avestruces con los que se llegó a experimentar informaciones recogidas en los Bestiarios como la que aseguraba que digerían hierro. El propio San Alberto parece que lo quiso experimentar sin éxito. Casi todos los animales procedían de regalos algunos famosísimos como los citados en el caso del Staufen y sobre todo el famoso elefante que San Luis le ofreció al rey de Inglaterra. ¿Y que decir del primero, una especie india, que Harun Al Rachid le regaló a Carlomagno para felicitarle por su título imperial? Todavía, y a pesar de no ser un desconocido, el paquidermo exhibido en la feria de Francfort en 1443 suscitó una enorme atención.

Debemos subrayar que no sólo los monarcas coleccionaban animales. Emulando a éstos los eclesiásticos, monjes, aristócratas, burgueses y hasta los municipios se subieron al carro de la vanidad y compitieron entre sí. Desde la primer referencia de un zoológico que hasta tenía un sistema divisionario para las especies, el del monasterio de San Gall en Suiza, en el siglo $x$, a las colecciones de animales de los Duques de Borgoña y Berry en Francia, las referencias serían larguísimas. La halconería del Duque de Orleans, por ejemplo, rivalizaba con las del propio rey de Francia ya que, además de las rapaces, ostentaba la nada despreciable cifra de cien perros especializados en caza mayor y menor.

Resumiendo, el coleccionismo animal respondió a motivaciones varias $y$, según las circunstancias, puede explicar el fenómeno de los zoológicos en los diferentes países europeos. A medida que pasa el tiempo las noticias sobre animales en cautividad se multiplican y la fauna no sólo se circunscribe a una demostración de poder y lujo sino que deriva hacia animales de compañía desde los fieros leones, suponemos que amansados, hasta monos y aves. Baste recordar estas últimas, los pájaros cantores de Carlos IV de Francia, que jugaron lo que hoy llamaríamos «terapia antiestrés» en los momentos depresivos del monarca quien se trasladaba con ellos en sus jaulas para escuchar sus cantos. 


\section{El caso de la Península lbérica}

El estudio de la fauna, más propiamente la salvaje o silvestre, en la península ibérica medieval abarca diferentes ámbitos y dimensiones. Probablemente uno de los aspectos más sobresalientes sea el referido a las especies cinegéticas autóctonas. Variadas son las fuentes, tanto escritas como iconográficas, pasando por la normativa legislativa, que nos informan sobre las especies cazadas o cazadoras. Las noticias sobre mamíferos y aves pueblan desde los tratados de caza hasta los capiteles de los claustros. El hombre medieval hispano, pues, estaba familiarizado con lobos, osos, zorros, jabalíes,corzos, halcones y grullas entre otras especies. Buena parte de los animales eran, además, objeto de reflexión en los Bestiarios y demás literatura moralizante pero también en otra cada vez más secularizada. Las especies silvestres autóctonas eran, con cierta frecuencia guardadas en los parques y jardines, especialmente los cérvidos pero también, aves y peces a modo de coleccionismo y no necesariamente para ser cazadas ${ }^{8}$.

Las mismas causas que se han expuesto para el desarrollo del coleccionismo animal europeo pueden aplicarse a España. Sin embargo, existen algunas diferencias con nuestros vecinos. La más llamativa fue naturalmente la presencia en nuestro suelo de la civilización musulmana también aficionada a mantener animales en cautividad como lo demuestra el parque zoológico de Medina Azahara.

España tuvo una gran tradición de espectáculos animales siendo la península el segundo lugar donde los romanos construyeron más anfiteatros después de Francia e Italia, naturalmente. Actualmente aun conservamos las corridas de toros, las cuales, con independencia de que su origen pudiera ser anterior a la dominación romana, sin duda constituyen hoy en día lo más parecido a los sangrientos espectáculos circenses romanos.

En la península ibérica también se prodigó la caza. La riqueza cinegética hispana era, y continua siendo, muy grande tanto para la caza mayor como menor. Contamos con suficientes datos para afirmar que buena parte de esa fauna era también conservada en recintos tanto para cazar como por el simple placer de poseerlos: lobos, osos, todo tipo de cérvidos... Además de las colecciones navarras, particularmente las del castillo de Olite, los monarcas castellanos, especialmente Enrique IV, ha

8 Morales MuÑIz, A. y D.C.: « ¿De quien es el ciervo? Algunas consideraciones en torno a la fauna cinegética de la España Medieval», comunicación (en prensa) presentada en el Congreso: El Medio Natural en la España Medieval, celebrado en Cáceres en 1999. 
pasado a la historia por su afición a las animalías o fieras que guardaba celosamente en El Pardo, Valsaín o Coca. Los monarcas de la Corona de Aragón, como Pedro IV el Ceremonioso o Martín el Humano trajeron cérvidos para repoblar el parque o pabellón de caza de Valldaura. El primero trasladó unas especies, que probablemente eran gamos, de Mallorca. Martín el Humano los hizo traer de tierras aragonesas.

En el comercio reside la tercera explicación para explicar la presencia de animales exóticos y, por ende, las menageries, en suelo hispano. La península gozó de una espléndida situación por su proximidad con el norte de África origen de la mayor parte de los animales contemplados en este estudio. Incluso la posibilidad de importar especies de lugares más lejanos no hubiera sido imposible por cuanto Al Anadalus estaba dentro de todos los circuitos que el mundo musulmán dominaba. Por ejemplo, el búfalo acuático o carabao, al que haremos referencia más adelante, no procede originalmente del norte de África sino de Siria.

Finalmente, y también por hallarse la península entre los mundos cristiano e islámico las embajadas, expresión por excelencia del mundo de la diplomacia, se producían con cierta frecuencia. Los regalos eran, en palabras de M. A. Ochoa, «signo de cortesía y hasta de captación de voluntades» teniendo el regalo un carácter que trascendía a lo puramente formulario introduciéndose en el contenido mismo de la acción diplomática. Dentro de las categorías del regalo los animales jugaban un papel esencial. Tanto los animales domésticos como los salvajes eran enormemente apreciados. Desde perros de caza, gatos, aves rapaces hasta los puramente exóticos, jirafas o cebras, la fauna jugó un importante papel en el mundo del intercambio de cortesía. Destacamos por su trascendencia -en el sentido de aportar varias especies exóticas - la embajada que el sultán mameluco Baybars hizo a Alfonso X El Sabio. La información está recogida por los cronistas y ha sido mencionada por varios autores ${ }^{9}$.

En definitiva, por su tradición circense, su afición a la caza, sus relaciones diplomáticas y comerciales, la península ibérica reunió todas las circunstancias para que la presencia de los animales exóticos fueran, en la España medieval, una realidad. Debemos hacer una pequeña apreciación: exotismo siempre se asocia con espectacularidad o rareza de una especie, parece que llevaría implícita su exhibición. Nadie con-

9 M. A. OCHOA: Historia de la diplomacia española, 6 vols., Madrid, 1986, realiza un magnífico repaso en el vol. III, pp. 402-409, sobre esta cuestión. El dato sobre la embajada está recogido en la p. 8 de las Crónicas de los Reyes de Castilla, de C. Rossel, 1953, BAE, 66. 
sideraría, por ejemplo, exótico al meloncillo pero en este trabajo que fundamentalmente quiere contribuir al estudio del coleccionismo de animales no autóctonos o exóticos, también haremos referencia a especies introducidas en nuestro suelo que en algunos casos todavía conviven entre nosotros. En el caso de otros animales como los carabaos o los camellos habría que preguntarse cuales fueron las causas de su desaparición. Sabemos que esa cuestión excedería a este trabajo pero no pueden dejar de cuestionarse si la invasión musulmana pudo aumentar nuestra fauna al introducir especies desconocidas. Noticias sin contrastar hablan desde un tipo de zorro - particularmente el zorro del desierto- el puerco espín, la tortuga morisca, y la mona de Gibraltar entre las especies más llamativas. Pero también menciona hienas,leopardos y ciervos de la Berbería, cuyos restos pudieron encontrarse a finales del siglo pasado ${ }^{10}$.

Las fuentes para el estudio de la fauna exótica -independientemente de su coleccionismo- son varias. No es posible determinar cuales son más importantes ya que depende de las variantes regionales. En ocasiones sólo una única noticia determina nuestro conocimiento de una especie lo que convierte a esa fuente en muy importante al ser prácticamente única. En principio, de manera general, el papel esencial lo jugarían las fuentes narrativas, las crónicas. Los libros de viaje, para nuestro trabajo ha sido esencial el que escribió Jerónimo Muntzer a finales del XV, los herbarios y hasta los Bestiarios proporcionan noticias de gran interés. En este último caso si bien se trata de un género moralizante que en muchas ocasiones no sólo hace que resulte difícil la identificación, por no decir que la lleva a la confusión, sin contar con que la etología resulta en ocasiones disparatada, algunos autores apuntan que los Bestiarios resultan de gran importancia para el estudio científico de la zoología ${ }^{11}$. Por ejemplo, sabemos que en los siglos europeos el único mono que se podía conocer es el Maccaca sylvanna porque era el que no tenía cola y así se describe en los Bestiarios. Una mezcla entre Bestiario y tratado mágico-medicinal sería El Libro de las Utilidades de los Animales, una interesante fuente para el estudio de la fauna exótica con algunos datos aplicables a nuestras espe-

10 Salvador CALDERÓN: «Influence de la domination arabe dans la faune de l'Andalousie», Le Naturiste, Revue Illustrée des Sciences Naturelles, XIV, 1892, pp. 96-99. Este curioso artículo lo encontré en los archivos de la Casa de Velázquez en Madrid.

${ }^{11}$ Es del todo meritorio el trabajo de análisis y sistematización realizado por $W$. GEORGE y $B$. YapP en The Naming of the Beasts. Natural History in the Medieval Bestiary, en el que, los autores reivindican las capacidades de los Bestiarios para escribir seriamente sobre la ciencia medieval. Londres, 1991. 
cies $^{12}$. Las fuentes jurídicas, son, asimismo, interesantes. Si bien convendría subrayar que, para este trabajo, y por razones de espacio, no se ha aumentado la investigación con información procedente de la normativa legislativa que, en algún caso, hubiera podido aportar datos inéditos sobre fauna no autóctona. Pero probablemente la fuente más directa para conocer la existencia, mantenimiento, traslado, y otras situaciones de la fauna sería la documentación económica/fiscal como las órdenes o libramientos a los cuidadores así como las cartas de algunos monarcas muy interesados en sus animales. Los vocabularios comerciales y aduaneros, donde se describe la especie viva o algunos de sus restos (pieles, huesos, plumas, púas...) son esenciales para el conocimiento de la fauna.Las fuentes iconográficas o artísticas tampoco pueden olvidarse si bien, probablemente por falta de dedicación, no son muchos los animales exóticos que aparecen plasmados en las distintas posibilidades de la imaginería, exceptuando, quizás, a los leones. Por último, los diversos géneros literarios aportan ejemplos de la presencia -incluso por primera vez en la lengua vernácula - y confirmación de la fauna exótica.

Todas las fuentes hasta ahora mencionadas son escritas o iconográficas. Sin embargo es del todo esencial que subrayemos la trascendencia de las fuentes materiales. La conservación de los restos del animal, particularmente sus huesos, confirman o refutan todo lo que la fuente escrita dice. La Arqueozoología es la única fuente que garantiza la identificación de la especie entre sus muchas aplicaciones. Desafortunadamente este trabajo apenas cuenta con alguna referencia si bien, como en el caso de la gineta, ha demostrado, como veremos, la seguridad que supone encontrar los huesos de cara a la identificación de la especie y lo que de aquellos puede derivarse. Muchas publicaciones de estas características demuestran nuestra afirmación. En mi caso, además, debo agradecer al Prof. Dr. Morales Muñiz, arqueozoólogo, la enorme paciencia para desentrañar la identificación de algunas especies dada la dificultad de interpretación que en ocasiones supone la información escrita. A él también le debo el apéndice recogido al final del trabajo con todas las especies citadas en el artículo con su clasificación lineana ${ }^{13}$.

12 Libro de las Utilidades de los Animales. Prólogo traducción y notas de Carmen Ruiz Villasante, Madrid, 1980. Este trabajo, probablemente del siglo XI, escrito por el médico sirio Ibn Baytisuc es, en palabras de su estudiosa, una mezcla de ciencia y folklore, además del valor artístico añadido de la miniatura, especialmente por el realismo de los animales a pesar de su arquetipismo y simbologia.

13 Destacamos por su interés, a modo de muestra, un trabajo interdisciplinar en donde se estudia la frecuencia de 134 especies en 188 excavaciones europeas comparando la información procedente de la arqueozoología con la documental y artística de los Bestiarios. «Betes médiévales et familiarité: Animaux familiers de l'esprit, animaux familiers de la vie en Antropozoologica, 20, 2 semestre, 1994, pp. \|-40. 
Con la información proporcionada por las fuentes intentaremos explicar el lugar de procedencia y el de la estancia del animal en nuestro suelo. Abordaremos la funcionalidad de las diferentes especies, que son variadas, y no siempre lúdicas, como cabría pensar de un moderno zoológico. También se procurará explicar en que medida la mentalidad reinante acerca de la simbología del animal que se plasmaba en la literatura de ficción, y particularmente en los Bestiarios, pudo influir en la conservación y coleccionismo de estas especies. Somos conscientes que en este espacio sólo podemos presentar seriamente el tema y dejar constancia de su importancia sabiendo que queda aun mucho por investigar y que no todas la áreas geográficas de la península - particularmente Al Andalus- han recibido la misma atención por nuestra parte.

\title{
LAS ESPECIES
}

\section{Leones y demás félidos}

\author{
Cuando unas voces oyeron \\ Atronaban el palacio \\ Diciendo: !guarda al león! \\ ¡Mal muera quienlo ha soltado! \\ Entró gritando el gentío \\ Y el león entró bramando \\ Aquí dio una voz el Cid \\ A quien por milagro \\ Se humilló la bestia fiera, \\ Humildosa y coleando. \\ Agradecióselo el Cid, \\ Y al cuello le echó los brazos \\ Y llevolo a la leonera \\ Faciéndole mil falagos. \\ Aturdido está el gentío \\ Viendo lo tal, no acatando \\ Que ambos eran leones, \\ Más el Cid era el más bravo
}

Uno de los grupos clásicos en los zoológicos medievales eran los felinos, y de entre estos, los leones. La primera vez que aparece el término león en castellano se encuentra en el Poema del Mio Cid, en el episodio de los condes de Carrión. Dicho episodio, además, parece querer demos- 
trar la cotidianidad del animal, en el sentido de su frecuente presencia en castillos y fortalezas. También se produce la misma sensación de cotidianidad cuando el rey Alfonso X (Partida VII, tít. XV, Leyes 7 y 23) habla del león, entre otras bestias, como de un animal que los hombres podían tener en su casa y que estaban obligados a "guardar o tener apresados para que no hicieran daño». ¿Tan poco sorprendente resulta, a juzgar por la redacción de la ley, que se pudieran conservar animales salvajes incluso por los particulares? La carga simbólica del león explica la preferencia de coleccionar ese animal por encima de cualquier otro. Este felino representaba la majestad y tratándose de un animal estatutario por excelencia no había monarca que no tuviera leonera en castillo, palacio o jardín. En el caso castellano,dado el origen leonés del reino, la preferencia no necesita más explicaciones. Cuentos, leyendas, refranes y recetas mágicas perpetúan una reputación positiva que se remonta al bíblico león de Judá y a otras culturas antiguas en Oriente y Occidente. Si el hombre era el rey de la creación, en el mundo de los animales el león hacía sus veces. Jesús mismo, en los Bestiarios, es comparado con las virtudes del león. La literatura hispánica medieval muestra ejemplos suficientes del interés por el animal, baste como ejemplo el papel protagonista del león, con una clara carga antropomórfica, en El Libro de las Bestias (s. XIII) del magnífico Raimundo Lulio.

El origen del animal era la Berbería, término amplio que comprende buena parte del norte de África (Trípoli, Túnez, Argelia y Marruecos). Algunos autores especulan con que el león pudo haber vivido como una especie más en la península ibérica, en los tiempos medievales, cosa que parece muy improbable. Otra cosa bien distinta es que hubiera leones importados, tema objeto de estas líneas, o que sus pieles estuvieran, digamos, en tránsito ${ }^{14}$. Por las relaciones comerciales y diplomáticas que tanto la Corona de Castilla como la de Aragón tuvieron con el norte de África no parece que hubiera grandes dificultades en proveerse de leones. Con las noticias que actualmente tenemos produce la impresión que buena parte de los animales procedían de regalos. No siempre eran los soberanos musulmanes los emisores de aquellos regalos. Los monarcas europeos se regalaban, entre sí, leones, y entre los reyes peninsulares las noticias sobre regalos no son infrecuentes. Los reyes na-

14 R. Delort constata pieles de leones, también de guepardos y leopardos que pasaban por los puertos de Mallorca, Valencia, y Lisboa. Procedian del Magreb o de Alejandría. Cita una piel de león procedente de Barcelona que estaría agrupada con otras pieles de origen español. En Le Commerce des fourrures en Occident a la fin du Moyen Age, pp.170-1, Rome-París, 1978. 
varros,según información de la sección de Comptos, recibieron ejemplares de leones del conde de Foix. El rey Martín el Humano le regaló una leona a Carlos el Noble de Navarra. A Juan II de Castilla, a través de un cristiano genovés, le hizo llegar Abu Faris de Túnez dos leones amansados. Pero los monarcas hispanos también entregaron regalos leoninos a sus homónimos europeos. Los castellanos hicieron llegar una pareja de leones, con collares de oro, al rey de Francia en $14 \|$, según consta en crónica de Juan II. El rey de Aragón, en I316, mandó otros ejemplares a la ciudad de Florencia. Años más tarde, en I395, Juan I el Cazador, regaló otra pareja de leones al rey de Francia. Incluso existe una noticia sobre el zoológico municipal de Amsterdam que se nutrió de leones traídos por los mercaderes españoles ¿Realmente había un superávit de leones que permitía los monarcas hispanos regalarlos con tanta facilidad? ${ }^{15}$.

No es posible afirmar de entre todos los monarcas peninsulares quien gozaba de la colección de leones más completa. Las noticias para el reino castellano se concentran en libramientos para el mantenimiento de «animalías", y no muchas, y en descripciones de los cronistas sobre los lugares donde se conservaban las fieras. Juan II era muy aficionado a los leones amansados, sin duda nacían en cautividad, y los utilizaba con frecuencia en audiencias y desfiles. Hay noticias de la embajada de 1434 con uno de estos ejemplares a sus pies. Dos años antes, en Valladolid, los leones desfilaron en la comitiva probablemente con intenciones políticas y propagandísticas.La cuestión de la mansedumbre de los animales ante el hombre fuerte o virtuoso es un tema recurrente y no sólo en las hagiografías. Hemos comentado anteriormente el caso de El Cid recogido en su Poema. Juan II quería, probablemente, subrayar así su majestad y la capacidad del animal de "comprender» que se hallaba ante un ser superior o excepcional.

El cronista oficial del rey Enrique IV, Enríquez del Castillo, describe al monarca como un aficionado a la caza "de todo linaje de animales y bestias fieras». El rey, que según los que le rodeaban, tenía el aspecto de un león, conservaba a sus animales en los parques y bosques de El Pardo, y Valsaín, en Segovia, entre otros lugares. Muy aficionado a pasear por

15 Los datos para Navarra generalmente procedentes de la sección de Comptos, son proporcionados por J. R. MARtínez Erro: Olite, Corte de Reyes, Pamplona, 1970. Para Castilla ver la Crónica de Juan II, BAE, 68, 1953, p. 339, y M. GalBRoss: Correo Erudito, II, p. 176, 1941, también Seco de Lucena Muhammad IX, 1978, y el ya citado de Loisel, pp. 212-3. Los datos sobre la colección de Barcelona están recogidos en el magnifico trabajo de ADROER I TASsis, A.: «Animals exotics als Palaus Reials de Barcelona», Medievalia, 8, pp. 9-22, 1989. 
montes y dehesas, para estar mezclado con las fieras, había mandado «hacer edificios y sitios cercados de diversas maneras... e tenía (con los animales) grandes gastos...». En los mismos términos se expresa el cronista Palencia que hace referencias más profusas e intencionadas sobre las aficiones del rey, no disimulando su antipatía hacia el monarca y explicando sus gustos como una muestra de su extraño comportamiento «...recorriendo escondidos bosques e intrincadas selvas, persiguiendo fieras... huía del trato con las gentes. ...contándose entre sus amigos los que cuidaban de la alimentación de las fieras, ocupación que en aquel palacio no se tenía por indigna». No estamos muy seguros de cuales eran las condiciones de conservación de los animales..., aunque cabe deducir que las llamadas leoneras eran espacios reservados a modo de jaulas o fosos o cualquier otros espacio protegido para que el animal no pudiera hacer daño, caso de la Torre de las Atalayas en el castillo de Olite, en Navarra. Otro quebradero de cabeza eran los traslados de un lugar a otro dentro o fuera del reino. Muchos animales enfermaban o incluso morían. La documentación recoge toda esa casuística.

Los cronistas castellanos, pues hacen referencia a fieras, pero prácticamente en ningún caso describen las especies. Sin embargo no es difícil deducir que se trataba, entre otros animales de los siempre favoritos leones habida cuenta que en la Corte castellana siempre habian existido dichos ejemplares, y que, como apuntan algunos autores, cuando se habla de fieras, en general, se incluyen o refieren con exclusividad a leones y otros félidos. Si, en cambio, nos consta, la manutención de uno de estos ejemplares en el Alcázar de Granada a principios del siglo XVI aun viviendo la reina católica ${ }^{16}$.

También eran leones los animales que D. Rodrigo, el conde de Benavente, guardaba celosamente en su zoológico particular. Los nueve ejemplares convivían con lobos y el viajero alemán Muntzer observó, con sorpresa, como los animales se mostraban de una gran mansedumbre

\footnotetext{
16 Ver las crónicas de EnRIQUez del CASTILlo, Crónica del rey Enrique IV de este nombre por su capellán y cronista, LXX, Madrid, 1953, y ALONSO DE PALENCIA: Crónica del rey Enrique IV de Castilla, BAE, CCLVII, pp. 40 y 59, Madrid, 1973. M. A. LAdero Quesada en La Hacienda Real en Castilla, La Laguna, 1973, menciona piel de león en el arancel de los Reyes Católicos de 1491. Dicho arancel tenía más de ciento cincuenta artículos lo que demostraba la variedad de riqueza del comercio sevillano. Citaba, además de la piel del león, animales o salvagina vivos: monos, gatos, papagayos, pp. 142-3. En la misma obra recoge M. A. LADERO, en el Sumario del año 1458, pp. 277, un libramiento de 17.000 maravedís a Juan de Córdoba para las animalías de El Pardo y a Pedro de Espinosa por el mismo concepto. Para el dato del león que los Reyes Católicos mantenían en el Alcázar de Sevilla ver R. Dominguez, Arte y Etiqueta de los Reyes Católicos, Madrid, 1993, pp. 206.
} 
conviviendo en paz entre ellos y respondiendo a las caricias de su cuidador, por más señas, un negro de imponente aspecto ${ }^{17}$.

Los reyes navarros también fueron muy aficionados a las colecciones de animales. El castillo de Olite tenía hermosísimos jardines, acogiendo un gran número de especies exóticas mezcladas con las autóctonas, como osos, lobos etc. El intercambio entre Olite y las tierras catalanas no parecía ser infrecuente particularmente con las colecciones reales conservadas en Barcelona. De todos los monarcas navarros fueron Carlos II y Carlos III amén del príncipe de Viana los más aficionados a las fieras y particularmente a los leones. Carlos III inventó unos artilugios para poder pasearles. Del mantenimiento de los animales parece que, como en el caso de la Corona de Aragón, pudieron ocuparse los judíos como se desprende de una orden de estipendio al cuidador ${ }^{18}$.

Anna Adroer en uno de los escasos trabajos españoles dedicados a los zoológicos ha analizado la existencia de los animales exóticos en las dependencias reales de la ciudad de Barcelona. Al menos desde el siglo XIII consta la existencia de leones en los jardines del Palacio Mayor bajo la muralla, trasladándose un siglo más tarde a una dependencia del Palacio Menor o de la Reina. Buena parte de la información sobre los animales nos la proporciona la documentación (Archivo de la Corona de Aragón) expedida para la manutención y cuidados a los que eran sometidos los animales, incluidos los complicados transportes. Los últimos soberanos de la Casa de Aragón se las vieron y desearon para recaudar dinero para ese fin y lo hicieron a través de los impuestos que gravaban sobre la aljama de la localidad correspondiente. Sabemos que en Barcelona, Valencia, Zaragoza (Palacio de la Aljafería) Calatayud (al fracasar Huesca) y Perpiñán, al menos, hubo leones que se mantenian a costa de los impuestos sobre las juderías.

Leoneros por excelencia fueron los judíos, una de las pocas relaciones que tiene este pueblo con animales. Contamos con un magnífico trabajo que nos permite conocer con todo detalle el sistema de mantenimiento de las fieras a través de estos leoneros judíos de baja extracción social, aunque gracias a esta actividad pudieron gozar de mayor prestigio entre sus hermanos de fe. También se nos informa sobre la predilección de los monarcas aragoneses-catalanes por los animales lo que les lleva-

\footnotetext{
17 J. Muntzer, Viaje por España y Portugal, 1494-95, Madrid, 1991, el dato está recogido en la p. 211

18 Martinez ERro: op. cit, recoge un documento de la Cámara de Comptos para que se pague al judío Abraham 45 sueldos por cada mes que tuviera la guarda de los leones, p. 17.
} 
ban, particularmente a Juan I a cartearse con el rey de Chipre para informarse sobre el afeitado de los cachorros. Es posible que los leones recibiera nombres propios, nos constan, al menos, dos, Anleón y Marzoc, este último objeto de regalo. Como regalos eran la mayoría de los leones procedentes de la cortesía de los dignatarios de Egipto y Bugía ${ }^{19}$.

A partir de I39| con la destrucción de los barrios judíos hubo de buscarse otros sistema para la manutención de animales. Será entonces cuando los funcionarios públicos se harán cargo de la cuestión (sous) Existía un guardián de leones, así como un sistema de recaudación en donde se establece una graduación entre los funcionarios. Finalmente los leones fueron mantenidos a través del dinero procedente de la venta de la piel de los animales, piel, por cierto, que aparece con alguna frecuencia en la documentación fiscal y aduanera. La colección zoológica acabaría siendo responsabilidad exclusiva de los consellers y la Casa de Leonera barcelonesa, dependiente del Palacio Menor, no desapareció hasta bien entrado el siglo XIX.

De todo lo expuesto, hasta el momento, parece deducirse que el propósito de conservar leones era exclusivamente lúdico. Parafraseando al cronista Palencia cuando hacía referencia a Enrique IV «encontraba placer en la contemplación de las fieras». También, como hemos repetido varias veces, se conservaba al animal por toda la carga simbólica que acababa formando parte de la propaganda política de los monarcas y así lo demostraban haciendo participar a los leones en desfiles, ceremonias y embajadas. Sin embargo, y esto sólo es un ejercicio de imaginación, sí es posible que los leones pudieran cumplir otros propósitos. De la redacción del ya citado título de la Partida del rey Sabio cabe pensar que quizás se utilizara el animal como guardián de propiedades y bienes, es decir, en calidad de defensa. Más difícil parece que pudiera participar en cacerías aunque también se ha especulado sobre ello.

No hemos hecho referencia a la existencia de leones en tierras andalusíes por falta de dedicación. Aceptando esa laguna sí puede afirmarse que, con respecto a la simbología podrían hacerse extensivos los comentarios que se han ido vertiendo aquí, para los cristianos, al caso musulmán... En las artes menores (telas, botes de marfil) y también en la escultura la imagen de león se usa con frecuencia. No olvidemos que estos

19 A. BLASCO: «La Casa de Fieras de Zaragoza y los judíos», comunicación presentada en el XV Congreso de Historia de la Corona de Aragón, Jaca, 1993. Añado las páginas originales de la comunicación, proporcionada amablemente, en su momento, por la autora, al desconocer las de la publicación, pp. 3-4. 
animales estaban asociados con la dinastía Omeya de Córdoba. También en los géneros literarios y en las crónicas, la imagen del león se usó profusamente. Como muestra recordemos al cronista Abd Allah cuando ejemplificó su tragedia, a raíz de la toma de Toledo por Alfonso VI y la llegada de los almorávides de Ibn Tasufín. Hallarse entre dos enemigos era comparable a "estar montado sobre un león». Ir montado en el animal representaba los sufrimientos pero bajarse... era la muerte ${ }^{20}$.

Si los cristianos tenían leones con más razón sería familiar el animal en tierras andalusíes. Otra duda nos asalta ¿podía utilizarse alguna parte del animal con fines medicinales? Los tratados de magia, herbarios y similares son, en la mayoría de los casos, un monumento al disparate pero tampoco es menos cierto que los compuestos de los animales, al igual que los de las plantas, han sido durante siglos utilizados para sanar. Alguien tan respetado como Avicena observaba que comer carne de león no era recomendable por la dificultad en digerirla. El mismo autor señala que la grasa del animal podía ser utilizada para los tumores y que, mezclada con aceite de rosas, resultaba óptima para tratar las fiebres crónicas. Comer el corazón de león curaba las fiebres cuartanas... y provocaba ser temido por los demás, según el Arte Cisoria de Enrique de Villena ${ }^{21}$.

Además de los leones parece probado que otras especies de félidos no eran desconocidas en tierras hispanas. Las fuentes medievales no parecen distinguir entre leopardo o pantera (Panthera pardus) y la onza o guepardo (Acynonyx jubatus) Zoológicamente hablando es un misterio saber a que animal se refieren cuando hablan de onza, leopardo, guepardo o simplemente... pardo. Para los Bestiarios el leopardo era producto de la unión de una leona y un "pardo" animal velocísimo que "se deja domesticar como un perro". Pardo, desde luego, no parece responder a ningún término científico si bien se ha señalado que los cruces entre animales silvestres eran improbables en su medio natural pero no en cautividad en

20 Para la significación de la iconografía animalística musulmana, en general, y también de los leones, ver los excelentes trabajos de Dr. J. ZOZAYA, especialmente «Algunas observaciones en torno a la ermita de San Baudelio de Casillas de Berlanga", Cuadernos de la Alhambra, 12, 1976, pp. 307. El dato de Abd Allah está recogido en R. BARKAl: Cristianos y musulmanes en la España Medieval: el enemigo en el espejo. Madrid, 1991, pp. 190.

21 En Código y Decálogo Medieval del manipulador de Alimentos (Presentación y Selección de Textos José Luis Martín) editado por el Ministerio de Agricultura, Pesca y Alimentación. Salamanca, 1995, se recogen varios extractos del Arte Cisoria, de Enrique DE VILLENA, de donde citamos nuestro dato sobre el león, p. 54. Ver también para cuestiones relacionados con la utilización de los animales en la medicina/magia, el Hortus Sanitatis (El Jardín de la Salud. Los Animales), Ed. Facsímil Universidad de León, Cátedra de San Isidoro, León, 1994. Las páginas del león en 146-7. 
donde podian producirse híbridos de algún tipo de gato o lince con leones. De lo que no cabe duda es que los leopardos aparecen en la documentación. Pedro IV el Ceremonioso, sin ir más lejos, envió al rey de Inglaterra una partida de animales salvajes, procedente de su comercio con África, en donde destacaba un leopardo. La onza, que aparece en el título correspondiente de Las Partidas, también está presente en el Libro de las Bestias de Lulio como una especie diferente al leopardo. Digo esto porque ambos animales son protagonistas de la historia y si fueran el mismo no tendrian porque duplicarse ni recibir nombres diferentes ${ }^{22}$.

Los guepardos aparecen citados en las colecciones de los reyes de Aragón y también, de 1357, consta que el rey de Navarra, Carlos II el Malo, poseía varios ejemplares en su palacio de Olite, perfectamente adiestrados. Esto último merece una pausa. Parece más que probable, y sería factible una mayor profundización en las fuentes escritas porque en las materiales se trataría de una lotería, que el leopardo corredor, también llamado guepardo o chita se utilizara en la caza siguiendo una costumbre musulmana u oriental. Esto último se comprueba en las descripciones que Marco Polo hace en su Libro de las Maravillas. Algunos autores, caso de Cummins, dan por hecho que la chita (cheetah) se utilizó con fines cazadores al menos en Italia siendo Federico II Staufen, tan conocedor de la cultura musulmana, el que tomó prestada la costumbre. Cuando hizo su entrada en Ravena, en 1231, iba acompañado por una guardia mora que portaba los animales si bien, al no existir muchos detalles cinegéticos sobre su uso, cabe pensar que su uso era ornamental. Desde luego estos animales no eran desconocidos para los zoológicos italianos, probablemente por sus relaciones comerciales con los lugares de origen del animal. Recuérdese la famosa "Gueparderie» de Nápoles y también el famoso zoológico de Florencia. Ahora bien, si no parece imposible que el animal hubiera pisado suelo europeo y que, incluso, se hubiera utilizado con fines cinegéticos, habría que revisar todas las fuentes iconográficas, prácticamente todas ellas italianas, en donde se ha identificado al guepardo o chita. Cummins cita un manuscrito italiano relativo a la caza y conservado en el Museo Condé, en Chantilly, cuyos márgenes están decorados con fantásticas miniaturas de animales cazadores, entre otros, chitas encollaradas y sujetas con correas. También cita un libro de apuntes en la Biblioteca Cívica de Bérgamo, con otra chita acollarada, un magnífico dibujo de este

22 Para los datos del leopardo ver YAPP \& GEORGE: op. cit., p. 54, y también, para el mismo animal ver en el Bestiario Medieval de I. MALAXECHEVERRIA, Madrid, 1986, pp. 264 y 28. Los animales, incluidos los guepardos, son citados, asimismo en el trabajo de ADROER I TASIS, A., p. 11. 
animal de Pisanello conservado en el Louvre. Personalmente hemos comprobado que son chitas los animales que aparecen en el fol. $51 \mathrm{v}$. de la miniatura "El encuentro de los Reyes Magos", incluido en Las muy ricas horas del duque de Berry, pero no es el caso de las pinturas de Gozzoli del Palacio Medici Ricardi de Florencia que, como se ha dicho en la Introducción de este trabajo, el supuesto guepardo ha sido identificado por el Dr. Morales como... un lince. ¿Podrian ser linces buena parte de las supuestas chitas dado que los errores se perpetúan en el tiempo? ${ }^{23}$

Probablemente el error también puede proceder de su confusión en las fuentes documentales, particularmente los tratados de caza, con el lince (Lynx pardina). Este animal, en concreto, recibía varios nombres: gato o lobo cerval, gato rabudo, incluso gato montés, que es otra especie (Félix sylvestris). Gastón Phoebus, conde de Foix, y autor de uno de los más afamados tratados de caza llama al lince... "chat leopard» probablemente por su piel manchada. Es posible, pues, que esto llevara a la confusión con las chitas ${ }^{24}$.

Si pasamos al caso hispano la situación no es menos confusa. Los manuales de montería no parecen, a primera vista, citar leopardos, cheetas y raramente aparece el lince. Ahora bien dado que cazar con chita parece un recurso musulmán no se puede descartar que se intentara entre los cristianos, incluso con otros félidos. R. Arié cita una prueba iconográfica cuando afirma que se cazaba con onza, que es la misma especie, y para ello se remite a la escena de caza del bote de marfil cordobés conservado en el Museo del Louvre y muchas veces reproducido en los libros de arte.

23 El dato de los guepardos adiestrados procede de G. Muñoz Goyanes: Noticias Históricas sobre la Caza en España (inédito), p. 24. J. Cummins cita los datos del guepardo o cheetah en su estupendo The Hound and the Hawk, N. York, 1988, pp. 31. MARco Polo: op. cit., cuando describe las costumbres cinegéticas del Gran Khan, p. 201, se refiere a leones, leopardos ( $\sin$ duda corredores o chitas) y linces que se adiestraban para atrapar todo tipo de animales, incluso muy grandes. No es difícil, pues, que se confundieran las especies. Cabe la posibilidad, además, que, también se utilizaran tigres al describirlos con «pelo hermosísimo y bello color porque son rayados a lo largo del cuerpo de negro, de rojo, y de blanco..grandisimos, más grandes que los de Babilonia (Egipto)".

24 Para el dato de G. Phoebus ver Cummins: op. cit., p. 150. Este autor, con respecto a la peninsula ibérica, de la que es un gran conocedor de las fuentes, añade que los linces no eran pieza apreciada en la caza, es más, casi no se refieren a esta especie en los tratados cinegéticos. Afirma que cuando se cazaban era casi por error o exclusión. No dice nada sobre el animal como cazador. Para el lince ver, también, R. GRANdE: El Lince Ibérico (Lynx Pardina) en Castilla y León, Salamanca, 1993. La confusión entre esta especie y los gatos monteses u otros "gatos" es monumental. Por ejemplo, ¿a qué llaman gato hormiguero o gato maymón los vocabularios comerciales? Lo que sí está comprobado es que las pieles de todos los animales fueron frecuentes en la península ibérica según la documentación manejada, entre otros por R. DELORT: Les Forrures... (ver nota 15). 
Aquí sí parece más claro que el animal sentado a la grupa del caballo pudiera ser una onza o chita. También, abundando en esto, recordamos la frase hecha, aun repetida en nuestros días y que los estudiosos remontan su origen a tiempos musulmanes, de hacer algo «...a la chita callando». La explicación sería que cazar con este felino, o con cualquier otro animal similar, fue prohibido por el propio Alfonso $X$, lo que no impidió que se siguiera utilizando «...a la chita callando» 25 .

\section{Los pequeños: mamiferos e insectivoros}

«...Vimos en ella (la casa) una especie de gacela que es un animal que tiene almizcle. Es mayor que el zorro, la cabeza, boca y orejas, semejantes a las del armiño, el color negruzco, salpicado de manchas blanquecinas y grises, cola y patas de perro, animal colérico y furioso Estaba en una jaula de madera, atado con una cadena de hierro..."

Jerónimo Muntzer

Viaje por España y Portugal

Tenemos noticias algo confusas sobre la existencia del puerco espín en nuestro suelo durante la época medieval. De nuevo nos viene a la cabeza la duda expuesta a lo largo de este trabajo ¿a que se llama puerco espín?. Este roedor (Hyxtrix cristata) es una especie desconocida para España si bien los vocabularios de aduanas, particularmente en la Corona de Aragón, nos indican que era muy estimado por sus púas. El ya citado trabajo de $\mathrm{S}$. Calderón, con todas las sospechas sobre su fiabilidad científica al ser tan antiguo, afirma que el animal existió en Andalucía y Extremadura hasta bien entrado el siglo xIX, habiendo sido, naturalmente, introducido por los musulmanes. Nos inclinamos a pensar que quizás lo que se llama puerco espín sea simplemente un erizo, mamífero insectívoro que, aun entre los campesinos asturianos, recibe el nombre de "porrucuspín». Sin embargo, para complicar más las cosas, lo que llaman erizo en los Bestiarios, parece tratarse, en realidad, del puerco espín «pequeño animal que tiene apariencia de puerco y está todo lleno de púas». Aunque lo de pequeño resulta que no es verdad, el comportamiento del animal de comer racimos de uvas, y por ende, destrozar las viñas, nos hace dudar sobre la especie. Aunque la información recogida en los Bestiarios y literatura si-

25 Para el dato de la onza, R. ARIÉ: La España Musulmana s. VIII-XV, Barcelona, 1988, pp. 315. Para el dicho sobre la chita ver J. Calles Valés y Bermejo Meléndez, B.: Dichos y Frases Hechas, Madrid, 1999, p. 221. 
milar no prueba, necesariamente, que el animal viviera en España. Noticias arqueozoológicas demuestran la existencia del animal, en época medieval, en Ceuta y otros lugares norteafricanos. Total: lo que se llama puercoespín podría ser un erizo y lo que los Bestiarios denominan erizo podría tratarse de un puerco espín ${ }^{26}$.

Se especula, asimismo, que el zorro del desierto, una especie desconocida en nuestro suelo, pudo haber sido introducida por los musulmanes en época medieval. Aparte del pintoresco artículo de S. Calderón un medievalista de la talla de $R$. Delort habla de que los peleteros hacían referencia a un tipo de piel de zorro, denominada por más señas, «español», que él quiere identificar con el zorro del desierto. Las pieles en tránsito, no obstante, no prueban la presencia física y viva del animal ${ }^{27}$.

Otro pequeño carnicero ajeno a nuestra fauna autóctona pero que aparece citado profusamente en la nomenclatura del comercio medieval de pieles es la marta cibelina. Parece que una de estas especies, la marta común, sí era autóctona.La documentación también habla de martas sicilianas. Pero la cibelina era la más apreciada. Nos faltan datos para afirmar si el animal fue introducido físicamente o si sólo tenemos noticias de sus pieles. Lo que sí parece fuera de toda duda es que lugares como Zaragoza fueron centros peleteros, y particularmente de martas cibelinas, a lo largo de todo el medievo desde la penetración musulmana en adelante.

De la familia vivérridos nos constan tres animalitos ajenos a nuestra fauna y que, al menos, en dos de los casos fueron introducidos por los musulmanes. Estos son la gineta, la civeta y el meloncillo o mangosta.La confusión entre las tres especies es monumental y no sólo entre ellas sino también con animales absolutamente diferentes como gatos y hasta gacelas almizcleras. Sólo de la gineta nos constan restos materiales, los primeros conocidos en Europa y de época almohade, como se demostró en un artículo de impacto internacional. Parece pues más que evidente la confirmación de que fue introducida por los musulmanes y que su piel —comprobada en la documentación aduanera y comercial- era apreciadisima sobre todo para forraduras. Delort, abundando más en el hecho recién comentado de su exclusiva introducción en España, afirma que las únicas pieles de ginetas procedían de nuestro país y proveían la demanda del mercado internacional. El animal, no

26 Riquelme, J. A. Y A. MoRALES: «A porcupine find from roman África with a review of archaeozoological data from cicunmediterranean sites», Archaeofauna, 6, 1997, pp. 91-5. Ver también para puercoespines, entre otras muchas especies de fauna, el interesante vocabulario de J. A. SESMA y A. Líbano ZUMALACÁRREGUi: Léxico del Comercio medieval en Aragón (s. xiv), Zaragoza, 1982.

27 Calderón, op cit., p. 98.También en R. Delort, Les Fourrures... pp. 170-1. 
obstante, pudo hacer las veces de gato al cazar ratones, y, quizás, quien sabe, si domesticado y utilizado de compañía ${ }^{28}$.

En el espléndido trabajo ya mencionado de A. Adroer se ha identificado como gineta a la "gacela almizclera" que Muntzer describe en su libro. Evidentemente, a nuestro juicio, no se trata de una gineta, pero también es verdad que no tiene nada que ver con una gacela. Al menos es, eso sí, de la misma familia. Nosotros creemos que el animal cuya descripción se ha reproducido al comienzo del epígrafe es una civeta, también denominado, en nuestra documentación medieval, gato de Algalia.

La descripción de Muntzer continua con el método para extraerle al animal el almizcle, una materia odorífera con grandes aplicaciones en el campo de la medicina y de la perfumería. La Viverra cibetha (zebad, en árabe) procede, entre otros lugares, del Norte de África, particularmente de Egipto y Abisinia. Muy estimada por el almizcle, que, por cierto, al ser un vivérrido también podría tenerlo la gineta de ahí la confusión del artículo de A. Adroer, la civeta hizo las veces de animal exótico y forma parte de presentes ofrecidos por los dignatarios musulmanes a sus homónimos cristianos.

Llama la atención, en la descripción de Muntzer, que describa al animal como agresivo, sin duda era así y por ello le tenían encadenado y enjaulado, pero no es menos cierto que el identificado como gato de algalia era la riveta y que eran muy estimados como compañía o mascota. Nos constan las órdenes de pago de la reina católica para los cuidadores de estos gatos. También en el arancel de 1491 aparecen citados gatos ¿serían los muy apreciados de Algalia? ${ }^{29}$.

Finalmente nos referimos a la tercera especie de vivérridos: el meloncillo o mangosta. Nos aparece en los glosarios comerciales como uno de los productos, con el nombre de melo. Los Bestiarios y literatura similar, concretamente el Libro de las Utilidades ... Ilama a este animal qur y de él se dice que "algunas personas afirman que se trata de un gato salvaje»

28 A. Morales: «Earliest Evidence of Genets (Genetta genetta, Mammalia, Viverridae) in Europe", Nature, 370 (6490) 1994, pp. 512-3. Para el dato de las martas cibelinas ver, además de la correspondiente entrada en el vocabulario citado en la anterior nota, M. GuAL CAMARENA: Vocabulario de comercio medieval. Colección de aranceles aduaneros de la Corona de Aragón s. XIII-XIV. Tarragona, 1968, p. 357.

29 Aparte del dato proporcionado por Muntzer tenemos información sobre los cuidadores de los gatos de Algalia de la reina católica en A. PRIETO: Casa y Descargos de los Reyes Católicos, leg. 9 , fol. 131 ; leg. 2 , fols. 98,99 y 217 ; leg. 6 , fol. 16 , Valladolid, 1969 y en el citado arancel (ver nota 16) de 1491. Seco dE SERRANO, op. cit, proporciona el dato sobre el regalo de la embajada de Abul Faris de Túnez a Juan II, en este caso un gato de Algalia, p. 139. Para las aplicaciones del gato de algalia ver el trabajo de MAS y GUINDAL, J. Las sustancias odoriferas animales: el civeto o algalia. Madrid, 1941. 
¿hay más confusión? Lo que sí es verdad es que, de las tres especies de vivérridos, sólo la civeta ha desaparecido de nuestro suelo. Ginetas y meloncillos se han aclimatado con nuestra fauna autóctona.

\section{Los herbivoros}

«...y no ha pelo alguno salvo en la cola, la cual ha como camello..y el cuerpo ha mal hecho, sin talle... y las piernas muy gruesas y parejas, y el pie redondo todo carne, y tiene cinco dedos en cada uno con sus uñas, y no ha pescuezo ninguno... tiene la cabeza apegada..y las orejas muy grandes y redondas y farpadas, y los ojos pequeños... y doha de tener nariz, una como trompa, que es muy ancha arriba, y angosta ayuso todavía, más como manga que le llegaba hasta el suelo... y cuando ha gana, métela en el agua y bebe con ella.., y en estas guijadas... tiene dos colmillos tan gruesos como la pierna de un hombre, $y$ tan altos como una brazada."

Ruy González de Clavijo Embajada a Tamerlán

Era frecuente, en los siglos medievales, conservar en parques de caza o acotados a diferentes especies autóctonas. Esto es válido particularmente para los cérvidos que, por su docilidad, eran animales que podían vivir en semidomesticación. Ciervos, corzos, gamos, lo que las fuentes denominan gamuza, eran objeto de intercambios para la repoblación o introducción de la especie en determinados espacios geográficos. Estas especies, además, también eran objeto de consumo y tenían usos industriales. Pero, aparte de las especies autóctonas, hay constancia de otras importadas caso de los camellos, los búfalos, las gacelas y los muflones.

La gacela, del árabe qazala, tan frecuentemente citada en la literatura judeomusulmana simbolizando el amor, parece que fue un herbívoro muy común en la España andalusí y, más tarde, en el reino nazarita de Granada. En cuanto al carnello animal que, por excelencia, ejemplifica las condiciones de la vida del beduino, tenía múltiples usos en el Islam. Además de montura y bestia de carga, se bebía su leche, y, en ocasiones su carne, aparte de utilizar su piel. Es un referente común en la literatura musulmana ocupando el primero de los lugares de entre todos los animales citados en el Corán.

J. Zozaya opina que el camello, al igual que el elefante, tenía un sentido mayestático y hasta religioso, como se comprueba en las manifestaciones iconográficas, caso del bote de marfil de Medina Azahara, en donde el animal lleva un palanquín. Para este especialista el camello era usado en Al Andalus de forma restringida con funciones nobles y en el ceremonial de Corte. 
Los camellos fueron importados a Al Andalus en el último tercio del siglo $x$ enviados por los Banu Yazar de Berbería. Almanzor los siguió trasladando para su utilización como bestias de carga y también para sus razzias. A finales del siglo XI participaron en la batalla de Zalaca y aun en el siglo XIV pastaban en Vera, Almería. Los autores no se ponen de acuerdo si el animal desapareció de la península por falta de aclimatación, lo que sí es verdad es que fueron objeto de regalo. Todavía en 1334 el Suitán de Marruecos Abu Hassan le hizo llegar un ejemplar a su homónimo castellano ${ }^{30}$.

Los búfalos de los que habla R. Arié, citando fuentes árabes, era un animal procedente de la India e introducido por los árabes del Sind en Iraq. Los árabe sirios lo trajeron, en su momento, a la península, quizás tan pronto como en siglo VIII O IX. Hay que volver a recordar que no se trata de un búfalo africano (Sincerus caffer) sino del carabao o búfalo acuático (Bubalus bubalus). Los Bestiarios cristianos hablan de este animal al que, en ocasiones confunden con el uro, y la literatura homónima musulmana señala la excelencia de la leche de la hembra de la especie, rica y espesa con la que se podía elaborar queso. Este último dato corroboraría la identificación del carabao que es la especie introducida en Al Andalus en donde los mercados vendían queso de búfala, lo que hoy denominaríamos mozarella. No sabemos tampoco a que especie pertenecieron los búfalos regalados al rey de Navarra por el Sr. De la Baronía de Aljafarín. Aunque parece difícil que pudiera tratarse de una especie africana.

En cuanto al muflón (Ovis musivov) sobre el que tenemos referencia del consumo de su carne, según el Arte Cisoria de Enrique de Villena, todavía en el siglo XV, se afirma que procedía de Mallorca. El dato es erróneo. No hay muflones en Mallorca si bien no puede descartarse que la especie fuera introducida en la isla en algún momento de la invasión musulmana.

De todos los herbívoros citados hasta ahora —muflón, búfalo, camello y gacela - hay que subrayar que también tuvieron usos dietéticos, excepto, quizás, el camello, y además, según la documentación fiscal procedente de las aduanas eran apreciados sus pieles, huesos, cueros y astas.

30 Aurora Ribagorda Calasanz ha examinado, entre otros animales, al camello a través de los textos canónicos musulmanes en Los Animales en los Textos Sagrados del Islam (Memoria de Investigación de la Licenciatura ), 1999, inédito. Un amplio resumen ha sido publicado en ETF. Serie III, 12, pp. 10-138. Ver también R. ARIÉ: op. cit., p. 228, y J. ZOZAYA: op. cit., pp. 325-6. Ver, para dromedarios, Morales, A.; RiQuelme, J.A., y C. LiSEAU: «Dromedaries in antiquity: Iberia and Beyond", Antiquity, 69 (263), pp. 368-375. Este último trabajo demuestra la presencia de este animal en la época medieval, a través de las fuentes arqueozoológicas, en las provincias de Madrid, Cartagena, Coimbra y Granada. 
Sin embargo, los herbívoros exóticos por excelencia fueron las cebras, rarísimas, sólo encontramos dos noticias sobre ellas - los elefantes y las jirafas. Los tres animales aparecen plasmados en uno de los pocos documentos iconográficos de fauna salvaje: una Cantiga de Alfonso $X$ que, sin duda, se vio influida por la famosa embajada de Baybars que trajo, a modo de regalos, a los animales, y dejó honda impresión en los contemporáneos ${ }^{31}$.

El elefante fue un animal muy conocido en la Antigüedad. En Oriente era montura de dioses y en el mundo clásico grecorromano, especialmente en Roma y también por los cartagineses, fue utilizado con fines militares. También participó en los crueles espectáculos circenses. Los Bestiarios medievales se hacen eco de los usos bélicos del paquidermo cuando describen las torres de madera que podían transportar a sus lomos con capacidad para cuarenta o cincuenta hombres. El Libro de Alexandre (s. XIII) que recordaba la vida del héroe macedonio describía así el ingenio bélico de la torre:

\section{"Traían los elefantes de castillos cargados que son bestias valientes y muy apoderados..."}

Los elefantes tamíbién eran mencionados en los Bestiarios medievales como símbolo no sólo de fortaleza sino también de castidad. Hasta en las casullas de los sacerdotes se bordaba el animal en clara referencia a esa virtud. Curiosamente el elefante era una especie infrecuente, por no decir desaparecida de las tierras europeas, y por ende hispanas, desde el comienzo de los siglos medievales. Sin embargo en la imaginería medieval era muy frecuente, probablemente por sus referencias en los diversos géneros literarios. Desde la escultura a los libros miniados pasando por las sillerías de los coros o las portadas de las iglesias -recuérdese la de Santa María de Olite - el elefante estuvo presente en la vida del hombre medieval... aun sin haberlo visto físicamente. Esto último lo achacaba San Isidoro a que el animal procedente de la Berbería ( $i$ ?) se había extinguido en los últimos tiempos romanos existiendo solamente la especie india, de lógicamente, difícil exportación. La realidad es que ambas especies -africana e india- se conocían bien en el medievo a través de la iconografía. En Bizancio, en cambio, se les reconocía físicamente distinguiéndose ambas especies por su funcionalidad: los hindúes domesticaban al animal

31 G. Menéndez PIDAL: La España del siglo xill leída en imágenes, Madrid, 1986. En la Cantiga 29, p. 294, se lee «Todas las criaturas deben honrar a Santa María». Aparece un dromedario, un león, un elefante, una jirafa, una cebra, y varias aves, entre ellas ¿un avestruz? 
y los africanos lo cazaban. El ejército imperial bizantino tuvo que enfrentarse con estos animales que eran utilizados por sus eternos rivales, los persas, y se cuenta que el emperador Heraclio hizo un entrada triunfal en Constantinopla en un carro tirado por cuatro elefantes que fueron, después, exhibidos en el Hipódromo y en el circo. Pero ni siquiera en el Imperio cristiano oriental el animal era frecuente en la vida cotidiana por más que fueran tomados como botín de guerra. Siempre eran motivo de sorpresa, regalo apreciado e inspiración artística como se comprueba en los mosaicos y trabajos de marfil ${ }^{32}$.

En Occidente los elefantes fueron objeto de regalo preferente en las embajadas de los grandes dignatarios como en los casos ya comentados de Harun Al Rachid a Carlomagno y el de San Luis al rey de Inglaterra. Este úitimo debió tener amplia repercusión entre sus contemporáneos ya que existe una Cantiga del Rey Sabio en donde se recuerda la efemérides. Por cierto, la especie representada es africana.

Muy pocos debieron ser los ejemplares conservados en la península. Contamos con una noticia, proporcionada de nuevo por J. Muntzer, del zoológico del conde de Benavente, en donde, entre otros animales, se conservó un paquidermo...que murió al poco tiempo de su traslado a causa del frío. El embajador de Enrique III, el madrileño Ruy Díaz de Clavijo, describió al animal que tuvo ocasión de ver en su viaje a la Corte de Tamerlán, como hemos reproducido en el comienzo del epigrafe.

Del segundo de los herbívoros, la cebra, nos consta su existencia por la descripción de la Crónica de Alfonso $X$ como «una asna que buiada y tenía una banda blanca y otra prieta». El mismo monarca en la Tercera Partida, título III, habla de «zebra» como un animal silvestre sin embargo no sabemos si se refiere, y no debe confundirse al tratarse de otra especie, del encebro $u$ onagro, un asno silvestre extinguido en el siglo XV1. Era especie autóctona que vivió durante todos los siglos medievales ${ }^{33}$.

Sin embargo la sensación de exótismo más clara la debió de producir la jirafa, un animal verdaderamente impactante cuya primera mención, según los especialistas, procede de la crónica de Alfonso XI. Sin embargo la "azorafa» era muy popular en Al Andalus antes de aquel regalo. $\mathrm{H}$. Pérès citando fuentes cronísticas musulmanas relata que en el 994 Zirí

32 S. Sebastí́n: El Fisiólogo atribuido a San Epifanio seguido de El Bestiario Toscano, Valencia, 1986, los datos sobre el elefante, p. 275. MARCO POLO, op cit., p. 268.

33 M. TeRrón Albarán: «Los asnos salvajes, cebros o encebros en la España Medieval y Extremadura: aspectos históricos, geográficos y caza». Memorias de la Real Academia de la Extremadura de las Letras y las Artes, 1 (1983), pp. 413-74. 
Ibn Attiga le envió, entre otros regalos, una jirafa al todopoderoso Almanzor. El animal no resistió el viaje,y, muerta al llegar, fue disecada. Aparte de la embajada de Baybars, las jirafas siguieron llegando a la península en calidad de regalos... De todas maneras la aclimatación era dificultosa. El historiador Ibh Khaldun, ya en el siglo xIV, describía a la jirafa como «un cuadúpedo de raro aspecto, talla colosal y que reúne los caracteres distintivos de varios animales de especies diferentes". Esa impresión de hibridismo la volvió a dar el embajador Clavijo en embajada a Tamerlán. Los poetas andalusíes como Ibn Hamdis dedicó en su Cancionero diecisiete versos a la jirafa y el embajador granadino Ibn Zamrak, que recordaba la piel del animal, no sabemos si en tierras andalusíes o norteafricanas, se inspiraba en ella para sus versos.Tanta influencia tuvo la jirafa en Al Andalus que en la fiesta de Mayruz - primer día del año solar coincidente con el equinoccio de primavera- había costumbre, a pesar de las prohibiciones de los juristas, de fabricar juguetitos con forma de animales. Las excavaciones arqueológicas demuestran que, de entre todos los animales, existía preferencia por las jirafitas ${ }^{34}$.

\section{Aves y peces}

«Los reyes de Castilla poseen aquí magníficos palacios de su propiedad... y muchos papagayos entre los cuales había uno de cinco colores, con la cabeza gris, el cuello verde, negra la pechuga, roja la cola y las alas azules terminando en verde...»

Jerónimo Muntzer Viaje por España...

Camina contoneándose llena de vanidad como la joven que arrastra la cola de su manto.

Ibn Jafaya

Peceras y pajareras eran habituales en las colecciones zoológicas europeas e hispanas. En cuanto a las primeras no sólo cumplían un papel lúdico sino que también funcionaban, en la mayor parte de las ocasiones, como piscifactorías. No debía ser el caso de la España Califal en donde se gastaban cantidades importantes para mantener las peceras de palacio.

34 Para los datos de la jirafa ver Miguel Angel Ochoa que ha resumido y revisado la historia de este animal en la diplomacia. Op. cit., p. 409, nota 457. H. PÉRĖs, Esplendor de Al Andalus, Madrid, 1990, p. 244. 
En Al Andalus, además se criaban tortugas (¿podría ser la Testuda graeca de la que habla S. Calderón?) y lagartos ${ }^{35}$.

Martín el Humano también se ocupó de criar diferentes especies en estanques pero no tenemos ninguna noticia sobre la introducción de especies no autóctonas lo que parece natural por la cuestión del transporte.Tampoco los que describen a los animales, y más en el caso de peces, pueden identificar las especies ni las fuentes documentales lo reseñarían como algo importante.

Otra cosa era las aves. Dejando a un lado las de presa, al tratarse de animales autóctonos, si bien alguna variedad puedo haber sido importada, o los gallos silvestres del valle de Arán conservados en Valladaura, las fuentes son bastante lacónicas. Aves salvajes son, según la Tercera Partida, título XXIII, los pavones, los faisanes y las gallinas de la India. No identificamos al último animal. $\mathrm{Si}$, en cambio, tenemos alguna información sobre las otras dos especies que fueron importadas probablemente por los romanos. Los llamados pavones son, en realidad, pavos reales, ya que el pavo, llamémosle de Navidad, es una especie americana., aunque algunas fuentes diferencian dos tipos de pavo o pavón. Los reales tenían una simbología muy positiva desde los tiempos del rey Salomón. En Roma gozaban de fama de incorruptibilidad lo que hizo que San Agustín tomara la idea y los convirtiera en signos de inmortalidad y resurrección. Aunque, en realidad, puede comprobarse en el arte paleocristiano que los pavos reales se plasmaban en las representaciones eucarísticas antes de San Agustín. Los Bestiarios y los Padres de la Iglesia continuaron asociando cristianismo y pavo real. El famoso grito o graznido del animal, se transforma en el del predicador o en el de la ira regis... Por toda su carga simbólica,y también por su belleza, estos animales fueron apreciadísimos y su función decorativa hizo que se convirtieran en huéspedes favoritos de jardines y parques lo que no impedía que también se consumiera. Los pavones que aparecen en la iconografía andalusí eran imagen, asimismo, de la inmortalidad siguiendo una interpretación oriental de la justicia y la veracidad divina. Los pavones con cuellos retorcidos son elementos funerarios que hacen referencia a la resurección de la dinastía Omeya enlazando a Oriente con Occidente. El famoso plato alcalaino de cerámica musulmana custodiado en el Museo Arqueológico Nacional es un ejemplo de la preferencia andalusí por este tema animalísti$\mathrm{co}$, que, tradicionalmente se ha asociado con una paloma pero seguimos la opinión del Dr. Zozaya en el sentido de que se trata de un pavón.

35 H. PÉRĖS, op. cit., p. 96. Para la tortuga morisca ver, además, artículo de S. Calderón. 
Los faisanes era también una especie importada nativos del Caspio y el Cáucaso entre otros lugares eran también apreciados como carne y como objetivo cinegético. También esta ave, a la que los Bestiarios tachan de «cobarde», cumplía una función decorativa si bien no resultaba tan espectacular como el pavo real.

Probablemente al igual que se trasladaron mamíferos los mercaderes trajeron aves exóticas de Oriente y más aun cuando se abrieron al intercambio las rutas africanas. Ya avanzado el siglo XV nos consta la descripción de Muntzer de la espléndida pajarera del Cardenal Mendoza. Pero mucho antes las había en jardines y palacios. Era famosa la de Medina Azahara con una gran variedad de especies.

Una de las aves exóticas más apreciadas fue el papagayo a pesar del ser muy infrecuentemente citado en los Bestiarios cristianos. Al proceder de varios lugares geográficos, generalmente tropicales, no es fácil saber el origen de estas aves. Parece que debía de ser común el procedente de Mauritania por ser muy adaptable y que puede coincidir con las descripciones de los Bestiarios, «...un pájaro muy bello todo verde con el pico y las patas rojas". Es probable que se tratara de un Psicatus krameri (vernáculo, loro) muy común en las savanas secas. Muntzer describe varios papagayos en su libro de viajes. Uno era el del infante don Enrique que tenía el cuerpo blanco y gris con unos bellos colores en el cuello. Identificado como un loro gris de Guinea en el trabajo de Adroer, se podía pensar que se trataba de un yako si no fuera porque esta especie no tiene colores en el cuello. Según Muntzer el animal no era parlante... porque no era verde, cuando estas aves tendrían facilidad todas para «hablar» al tener la lengua carnosa independientemente de su color. Curiosamente en la colección ornitológica del infante los que hablaban eran... los tordos, cosa perfectamente improbable.

También tenía papagayos el píncipe de Viana y los Reyes Católicos, particularmente la reina, fueron muy aficionados. La descripción a comienzos del epígrafe pertenece a uno de los animales de la colección de Isabel que tenía en Guadalupe. En el arancel de 1491, detallado en las fuentes hacendísticas, entre otros animales, aparecen los papagayos.

Pero sin lugar a dudas el ave más exótica e impactante fue el avestruz. Su etimología responde a un extraño compuesto de ave y otra especie. Una mezcla de «camello-pájaro». Estruz, que es el término que aparece en los documentación, los glosarios cinegéticos y en algunos Bestiarios parece proceder del occitano antiguo y, a su vez, deriva del latín y del griego. El primer documento en donde aparecen citados los avestruces en castellano es en Crónica de Alfonso XI (1340) formando parte de los re- 
galos que el Sultán de Marruecos Abu Hassan le hizo llegar al monarca. Pero los animales eran conocidos de antes. Ya existían en las colecciones de los reyes de Aragón y no debían de ser desconocidos en Castilla ya que en la crónica de Juan II se habla de un avestruz como regalo de este monarca al rey de Francia. Desde luego no era tampoco extraño al mundo andalusí en donde el poeta Ibn Jafaya le dedicó unos versos muy populares. Muntzer, de nuevo, describió un ejemplar que se conservaba en el castillo de Finiana, en Almería. El ave, a cargo del alcaide, fue mostrado a los ilustres visitantes admirados de su hermoso plumaje grisáceo. Los avestruces fueron también muy apreciados por dos productos comerciales citados en la documentación: los huevos y las plumas. Sobre los primeros, que, además, tienen toda una carga moralista y folklórica en los Bestiarios, los herbarios de la época añaden otra literatura de contenido mágico. Entre otras recetas se recomendaba que el interior de los huevos del animal, mezclados con miel y manteca, se usaran para curar la demencia. Los huevos, además, eran estimados en los gabinetes científicos renacentistas como motivo exótico. En cuanto a las plumas, lógicamente, su valoración procedía de su belleza y tenían un fin ornamental ${ }^{36}$.

\section{Los más exóticos: cocodrilos y monos}

"La mona es una bestia que quiere hacer todo lo que ve..."

Bestiario Toscano

«... tiene un principio pero no un final, esto es, no tiene rabo, de la misma manera que el demonio, al comienzo, era uno de los arcángeles, pero no se ha encontrado su fin....»

Fisiólogo

El término cocodrilo procede del latín vulgar cocatrix, una forma de calcatrix, derivado de calcáreo (pisar) que hace referencia a la forma de caminar del animal. Los Bestiarios hablan de la serpiente caltriz o calcatriz

36 La información simbólica sobre faisanes y pavones nos la proporcionan, en principio, los Bestiarios. Hemos seguido a S. Sebastián: El Fisiólogo..., entre otros trabajos citados ya en la nota 6. En cuanto los avestruces, particularmente el descrito por Muntzer, se encuentra en la p. 83. En el trabajo de Adroer las citas de estas aves, en la p. 11, también hay informaciones en LOISEL, PÉRES, op. cit., p. 37, sobre huevos y plumas en los vocabularios ya citados del comercio medieval. RuY DIAZ DE CLAVIJO en su Embajada a Tamerlán, describe un avestruz, aunque el animal no fue visto, naturalmente en España. Madrid, 1982. Por lo que se refiere a los papagayos, las fuentes son más o menos las mismas, el arancel de 1991, las informaciones proporcionadas por Muntzer, etc. 
un galimatías de imposible identificación ya que no se sabe si se refieren a una especie de lagarto... porque incluso añaden que podía confudirse con una mangota (¿?). Pero los Bestiarios también hacen referencia a los cocodrilos del Nilo de los que no dudan en escribir que se trata de fieras acuáticas depredadoras enemigas de todos los animales y del hombre. Naturalmente la asociación con el diablo está fuera de toda duda. En las muchas veces citada embajada a Alfonso $X$ se incluyó, a modo de presente, un cocodrilo que, al morir, fue disecado y colgado de una nave de la catedral de Sevilla que por ello sigue denominándose del lagarto. A finales del siglo xv Muntzer cita cocodrilos, peces sierra y pieles de serpiente procedentes de las rutas comerciales portuguesas con las africanas.

El último animal al que haremos referencia en este trabajo es la especie más «humana», el mono. De hecho simio procede de similar por su parecido con el hombre. San Isidoro en sus Etimologías subrayaba que también podía significar feo y narices aplastadas. Observa que es imitativo y que le gusta jugar con los niños. De hecho su revoltosa alegría le convertía en mascota insuperable. También es cierto que los Bestiarios subrayaban su carácter libertino y su cierta asociación con el demonio por aquello de no tener cola. Y es justamente el no tener cola lo que nos permite identificar la única especie de mono conocida en el medievo europeo...

Esta especie era originaria del Norte de África - Argelia y Marruecosde donde derivó hacia las tierras del sur de España, introducido por los musulmanes..La mona de Gibraltar todavía pervive hoy en el Peñón. Aparte de esta especie en los siglos medievales pudieron conocerse otros monos indios o africanos subsaharianos que pudieron ser traídos por marinos y comerciantes a modo de mascotas. Estas especies, generalmente de cola larga, como el cercopithecus o el baboon, como los descritos por Marco Polo, en algún caso podían tener un tamaño considerable lo que no les convertía en mascotas precisamente manejables, quizás se reservasen para exhibición, pero nos faltan datos para confirmar la información.

Tenemos poco apoyo documental para hablar de monos en la península, y sin embargo una investigación más profunda arrojaría, posiblemente, resultados muy positivos.Tenemos la impresión de que el animalito , por cuestiones «ideológicas», en donde no debe descartarse la influencia judeomusulmana, no era tan popular como en otros lugares de la Europa Occidental. En Inglaterra, por ejemplo, ya en el siglo xIII, había una Maestro de Loros y Monos del Rey. Los últimos correteaban alegremente y como buenas mascotas por los castillos con total libertad. Se sabe que Thomas Beckett ,embajador en Francia del rey Enrique II, viajaba con una menagerie itinerante en donde no faltaban los monos amaes- 
trados. Un cronista alude a esta afición ,típica de los clérigos, justificándola porque les liberaba de sus ansiedades ${ }^{37}$.

La información procedente de las aduanas, en la Corona de Aragón, nos hablan de «bogia» un mono procedente de Bugía (Argelia). También aparecen monos en el arancel de 1491. El mono gozaba de la peor de las reputaciones, a la par que el cerdo, entre los musulmanes. Era el insulto preferido para ofender a los judíos. Eso no significa que el animal no estuviera presente en la vida cotidiana de Al Andalus. Era corriente verlo con los titiriteros y los encantadores de serpientes y con ellos asustaban «a las mujeres». Los cronistas musulmanes hacen referencia a monos en varias ocasiones casi siempre de forma peyorativa. A Almanzor sus enemigos el llamaban mono marduzco (quird ashab). También se hace mención del mono que Alfonso VI de Castilla, el conquistador de Toledo, le regaló a su amigo Yihya ben Abd Malik, animal del que estaba orgulloso lo que, según el cronista era indicativo de su cortedad mental. Pérès, comentando este mismo episodio añade que Abd Malik no vio en el regalo ningún signo de menosprecio, quizás, decimos nosotros, ¿porque estaba ciego? ${ }^{38}$.

\section{EPÍLOGO: EL IMPACTO AMERICANO}

La diferencia fundamental entre las colecciones medievales y las de las centurias siguientes, a decir de los expertos, consiste en que las primeras eran elementos de lujo y exotismo y, un siglo después, se convirtieron en motivo de reflexión e interés científico por las curiosidades de la naturaleza. El siglo $\mathrm{xV}$, ya plenamente humanista o renacentista, resulta ser precedente de los que después será, en el XVI, las colecciones llamadas Cámaras de Maraviilas, a modo de moderno gabinete de ciencia, con animales disecados y el gusto por objetos de contenidos mágicos: Ienguas de escorpión, huevos de avestruz.

Aunque nuestro trabajo termina en el momento del descubrimiento del Nuevo Mundo no podemos dejar de subrayar las enormes posibilidades que se abrieron para Europa a través de España en materia de conocimientos faunísticos. El cronista Fernández de Oviedo, al describir aquella

37 La información sobre Thomas Beckett está relatada en el estudio de J. SERPELL: In the Company of Animals. A Study of Human Animal Relationships, Cambridge, 1996, pp. 47-8.

38 La anécdota sobre el regalo de Alfonso VI la cita RON BARKAl y PËĖs en sus obras. En el vocabulario de Gual Camarena, la entrada de bugia en la p. 240. S. CALDerón, op cit., p. 96. 
fauna american, descubrió animales fantásticos y desconocidos, algunos traídos casi de inmediato a la península. De entre las especies americanas destacamos algunas: los cories - o conejitos de Indias - los monos-gato, los manatí, cocuyos, en un principio, a los que se añadieron, con el tiempo pumas, coyotes, bisontes, osos hormigueros, zarigüeyas, pavos, caimanes, iguanas y muchas especies de serpientes. Todos ellos poblaron los libros y la iconografía de los siglos modernos. Los zoológicos pudieron exhibir la fauna más exótica y las colecciones de los incipientes Museos de Ciencias Naturales,como el de Madrid, albergaron las mejores colecciones conocidas en Europa. Aunque esa ya es otra historia no debe olvidarse que el antecedente estuvo en los siglos medievales en los que no se perdió el gusto por el coleccionismo animal.

Hemos intentado contribuir, con un estado de la cuestión, al estudio de los zoológicos medievales y a las especies introducidas en nuestro suelo durante aquellos siglos. Es, lógicamente, una información modificable en la medida que se puedan añadir datos procedentes de las fuentes escritas, y aun mejor, de las arquezoológicas. Este trabajo se ha realizado sin dejan de pensar en el homenajeado, Prof. Dr.Antelo, con cuya amistad y sabiduría me honró y con el que tuve ocasión de hablar de esta investigación, nueva para mí, a la que siempre me animó dada su amplia mentalidad, su curiosidad y el carácter interdisciplinar que practicaba en su investigación. Su recuerdo permanecerá siempre presente especialmente cuando escriba sobre estos temas en los tiempos medievales.

Clasificación lineana de los taxones mencionados en el texto

CLASE: REPTILES

ORDEN CRocodilia

Familia Crocodilicos:

Crocodilus riloticus, cocodrilo del Nilo.

ORden Quelonios

Familia Testudínidos:

Testudo graeca, tortuga morisca.

CLASE: AVES

ORDEN STRUTHIONIFORMES

Familia Estrutionidos:

Struthio camelus, Avestruz.

ORden PSitciformes

Familia Psicacidas:

Papagayos, loros, cotorras.

ORDEn Galliformes

Familia Fasianidos:

Pavo cristatus, Pavo Real, Pavón, Pavo

Phasianus colchitus, Faisán. 


\section{Clasificación lineana de los taxones mencionados en el texto (continuación)}

\section{CLASE: MAMÍFEROS}

ORDEN INSECTÍvOROS

Familia Erinaceidos:

Orden Primates

Familia Cercopithecidos:

Orden Carnivoros

Familia Mustélidos:

Familia Vivérridos:

Familia Hyenidos:

Familia Félidos:

Orden Roedores

Familia Histrícidos:

Orden Proboscideos

Familia Elefántidos:

Orden ARtiodáctilos Familia Camélidos:

Familia Bóvidos:

Familia Jiráfidos:

Orden Perisodáctilos

Familia Ëquidos:
Erinaceus europaeus, erizo, porrucusín.

Macacca sylvana, mona de Gibraltar, entre otras.

Martes cibellina, marta cibelina.

Genetta genetta, gineta.

Herpesthes icheneumon, melón, meloncillo, mangosta, melo. Viverra civetta, civeta, gato de Algalia.

Crocutta crocutta, hiena manchada.

Hyaena brunnea, hiena rayada.

Panthera leo, león.

Panthera pardus: pantera, leopardo.

Panthera uncia, leopardo de las nieves, onza.

Acynonyx jubatus, guepardo, chita, leopardo corredor, ¿onza?

Hystrix cristata, puerco espín.

Loxodonta africana, elefante africano.

Elephas maximus, elefante asiático.

Camelus dromedarius, camello, dromedario.

Syncerus cafer, búfalo africano.

Bubalus bubalis, búfalo acuático o carabao.

Ovis musimon, muflón.

Gazella sp. (más de treinta especies).

Amotragus laervia, ciervo de Berbería.

Jiraffa camelopardalis, jirafa.

Equus grevy.

Equus burcheli, cebras.

Equus zebra.

Equus hydruntinus, encebro. 